\title{
Using Action Research To Identify Unexpected Factors Affecting CRM Implementation
}

Assion Lawson-Body, University of North Dakota, USA

Laurence Lawson-Body, University of North Dakota, USA

Lori Willoughby, Minot State University, USA

\begin{abstract}
No action research has been conducted regarding the status of CRM implementation in the public institution sector. This study aims to identify rare or unexpected contextual, organizational, and individual factors behind the CRM implementation at a state SBDC. For this purpose, interview data was collected from 19 consultants of the state SBDC. Surprisingly this CRM implementation is considered particularly successful even though it involved only internal user participation for the individual factors. To be successful, CRM implementation must involve internal and external user participation. Our findings about internal user participation contradict the previous research. During the progression of the qualitative analysis, other rare or unexpected factors to the CRM implementation literature were found. These are: accreditation review pressure for the contextual factors and legal and licensing agreement feasibility for the organizational factors.
\end{abstract}

Keywords: CRM Implementation; Internal User Participation; Accreditation Review Pressure; Legal And Policy Agreement Feasibility

\section{INTRODUCTION}

\& ince CRM (customer relationship management) uses IT (information technology) as an enabler, the importance of its implementation has been revealed by different authors in both academia and industry (Mendoza, Marius, Perez \& Griman, 2007; Steel, Dubelaar \& Ewing, 2013). While some organizations successfully implemented their CRM systems, others are likely to fail (Steel et al. 2013; Garrido-Moreno, Lockett \& Garcia-Morales, 2014). For instance, Garrido-Moreno and Padilla-Meléndez (2011) found diverse studies that show high rates of failure when implementing CRM. One of the reasons behind the failure of CRM systems is the inefficiency during their implementation (Mendoza et al. 2007).

Many authors have conducted studies to find contextual, organizational and individual factors influencing CRM implementation (Lawson-Body, Willoughby, Lawson-Body \& Kinvi, 2012). Those factors affecting CRM implementation are widely spread in the literature. However, there is still no exhaustive list of the existing factors to guide companies to their successful CRM implementation (Garrido-Moreno \& Padilla-Meléndez, 2011; Lawson-Body et al. 2012). Consequently, the contextual, organizational and individual factors vary from implementation to implementation and there is no common way that will solve each company's implementation problems (Mendoza et al. 2007). This study is dedicated to find new, rare or unexpected factors associated with the CRM implementation.

Our goal is not to repeat, duplicate or to confirm the same factors already found in the CRM implementation. Rather, the objective of this study is to use existing IT and CRM implementation literature and theories to discover any rare or unexpected factors associated with the CRM implementation at a state SBDC (small-business development center) in which public and non-profit institution philosophy plays an important role. Lessons from this study should contribute to the successful implementation of CRM software at institutions with the same vocation as the state SBDC that receive grants and funding from governments. The main research question is: what are the rare or unexpected contextual, organizational and individual factors influencing a strategic CRM implementation at a state SBDC? 


\section{THEORETICAL BACKGROUND}

In 2003, Venkatesh, Morris, Davis and Davis (Sumak \& Sorgo, 2016) offered the unified theory of acceptance and use of technology (UTAUT) after benchmarking eight different models related to the IT acceptance in the literature. The eight models are the following: the theory of rational action (TRA), the technology acceptance model (TAM), the motivational model, the theory of planned behavior (TPB), the combined TAM and TPB model, the model of PC utilization, the innovation diffusion theory, and the social cognitive theory (Pai \& Tu, 2011).

Since its inspection, UTAUT has increasingly become a theoretical foundation used to explore the factors affecting the acceptance and use of different types of IT. As a matter of fact, Sumak and Sorgo (2016) proposed to extend the UTAUT with a new moderator variable user type in order to investigate differences in the UTAUT determinants between pre and post-adopters of interactive whiteboard systems. Tate, Evermann, and Gable (2015) used UTAUT to develop an integrated framework for theories of individual attitudes toward technology implementation. The UTAUT framework has also been used to study CRM implementation acceptance (Pai \& Tu, 2011). Therefore, this study proposes to extend the theory of UTAUT with new, rare or unexpected contextual, organizational, and individual variables found in the investigation of the implementation of CRM at a state SBDC.

\section{FACTORS AFFECTING CRM IMPLEMENTATION}

CRM implementation is influenced by issues that relate to contextual, organizational and individual factors (Steel et al. 2013; Alshawi, Missi \& Irani, 2011; Lawson-Body et al. 2012).

Contextual factors are mainly contingent to external environmental opportunities and threats that companies face (Porter, 2008) and that could have impacts on the CRM implementation process. Steel et al. (2013) mentioned that the contextual factors that appear to shape expectations of CRM are the norms of the industry and customers' attitudes towards suppliers. Steel et al. (2013) used a longitudinal case study approach with six cases to investigate the potential impact of contextual factors on CRM projects. They found that current industry conditions and customer expectations influence the reasons for implementing CRM.

Garrido-Moreno and Padilla-Meléndez (2011) found that organizational factors impact CRM implementation success. CRM requires a redesign of processes in order to connect the organization to the customers (Garrido-Moreno \& Padilla-Meléndez, 2011). Steel et al. (2013) found that the organizational context has a noticeable impact on the design and implementation of CRM. In a similar vein, Alshawi et al. (2011) found that CRM implementation is influenced by issues that relate to organizational, technical and data quality factors.

The individual factors are a set of identified patterns that describe a user attitude or behavior towards the CRM implementation process (Mahdavi, Cho, Shirazi \& Sahebjamnia, 2008). CRM user profiles contain (1) factual information about users, such as demographic and psychographic data, and (2) a set of rules that describes the behavior of users (Mahdavi et al. 2008).

\section{CASE BACKGROUND}

The small businesses (SBs) have been long recognized as important in US economy. They employ $50 \%$ of the active population and there are currently over 22 million SBs in the US which need and deserve to be served (Lawson-Body et al. 2012). One of the groups that serve SBs is the SBDC. In many SB services and training deliveries, there is a high level of interaction between SBDC consultants, staff, directors and SB personnel, representatives or managers. The most fundamental responsibility of SBDC is providing technical assistance to SBs. This is why a state SBDC decided to implement the CRM software program. The project was funded by a grant received from the US federal government, a regional university - College of Business and Public Administration (CBPA) - and local interests in a state in US.

The lead center of the state SBDC is composed of two people (Lawson-Body et al. 2012): the state director and the state associate director who is a faculty member at CBPA. There are 12 regional centers state wide and more than 19 consultants work in the regional centers (Lawson-Body et al. 2012). The state SBDC is hosted by the CBPA. 


\section{MOTIVATIONS FOR IMPLEMENTING A CRM SYSTEM AT THE STATE SBDC}

The activity recording and reporting system previously used by the state SBDC, 1-Site, was unsatisfactory. After noticing those problems, the state SBDC decided to improve 1-Site to fix the reporting data failure. The state SBDC raised funds for specific 1-Site enhancements, and continued its contracted hosting and server maintenance with 1Site vendor. Because redundant client records affect negatively the integrity of the SBDC database, the Small Business Administration (SBA) has advised all SBDCs to incorporate in their database, redundancy analysis report in order to detect any anomalies during the reporting process. The state SBDC 1-Site fails to incorporate this redundancy analysis report, therefore, wrong milestone accomplishments on record had reported to the SBA database. The state SBDC decided to investigate on a new solution for reporting data to the SBA database. Since CRM is about internal and external business processes of the firm, a CRM system replaces an existing way of dealing with such processes. Therefore, the main motivation is that CRM is believed to improve these processes and the reporting mechanism between the SBDC database and the SBA database.

\section{RESEARCH DESIGN AND ANALYSIS}

\section{Research Design}

Why action research for this project?

Historically, action research has been used the first time after World War II in studies of social and workplace issues (Kock, 1998). Action research emerged recently in the IS (Information Systems) field because it benefits both the researcher and the organization which is being studied (Kock, 1998). IS field has been considered as a natural application domain for action research (Wastell, Kawalek, Langmead-Jones \& Ormerod, 2004). The researcher usually studies a single small sample of organization in depth, using participant observation and interviews as data collection tools (Kock, 1998).

Action research involves scholars who themselves belong to the situation that is being researched and changes the way social and organizational system operates (Waser \& Johns, 2003). This research method is valuable because the researcher is part of the organization under study and changes the organization by solving his problem in terms of productivity and working conditions. Simultaneously, action research allows the researcher document, collect, analyze, and draw conceptual and theoretical conclusions from organizational research data (Kock, 1998).

The CRM implementation was the result of an action research project performed by a researcher in partnership with a state SBDC. The state SBDC benefits because the implementation of the CRM systems constitutes an improvement and a change in their working conditions. The state SBDC received a practical report containing recommendations about the installation, the maintenance, server requirements, reporting procedures and evaluations. The researcher also makes a gain from the situation because the action research method allows him to collect qualitative data using interview procedures and analyzed it using content analysis. Further, the researcher codified the data and validated it using inter-judge coding reliability procedure. A survey was also used to collect demographic data. Later, the researcher derived a publication from the final practical report. Finally, the researcher used that opportunity to learn more about the applicability of CRM implementation process in a public sector organization.

In action research, the researcher is an insider. In this study, the researcher participated in the project with his intellectual capacity and worked in group with the state SBDC lead center with frequent visits to the public institution, presentations at meetings, written memos, and presentation of final practical reports. Those visits help the researcher to perform: observations of meetings, collection of documents like internal papers, action plans, agendas, minutes, annual reports, US SBA grant application announcement documents, the state SBDC magazines and newsletters distributed to the SBs.

In action research, "action" (changes or improvements in the organization) and "research" (publication outcomes) are combined into a structured cycle (Kock, 1998). This cycle of action research steps of data gathering, data feedback, data analysis, action planning, implementation, and evaluation were executed (Nair, Malhotra \& Ahire, 2011). This method is suited to a case study research approach (Waser \& Johns, 2003). 
In the research process and analysis sections below, two main action research tools must be emphasized: a) interviews as data gathering tool and $\mathrm{b}$ ) content analysis.

\section{Interviews and Content Analysis}

Content analysis has been used in this paper because the phenomenon to be observed is communication, rather than behavior (Qu, Zhang \& $\mathrm{Li}, 2008)$. Interview data collection was focused on the CRM implementation process. We had face-to-face in-depth interviews with 19 SBDC consultants who took part in the implementation activities. Next, the interview guide was reviewed and approved by the institutional review board of the local university as prescribed by the university's policies and procedures governing the use of human subjects. The interviews, which lasted for about one hour, were unstructured and/or semi structured depending on participants' responses. All interviews were held in the participants' offices and audio-recorded with the permission of the interviewees.

The texts of the interviews were transcribed by our research assistants and entered into Windows Word software. The transcripts were double checked by the researchers and validated by the interviewees. The transcripts were sent back to the interviewees by email attachment for review and validation. Some transcripts required clarifications and those adjustments or corrections were made and incorporated in the final transcripts.

Each text unit in the interview transcripts was analyzed by two judges to determine whether it was related to CRM implementation or not and, if so, to which contextual, organizational, and individual factors it related.

\section{FINDINGS}

As shown in Table 1, the judges found 3 factors which fit in 3 categories. All the factors fell in the contextual, organizational and individual categories. Surprisingly, external user participation which is supposed to be part of CRM implementation was not found. During the progression of the qualitative analysis, some new or unexpected factors to the CRM implementation literature were found. These are: accreditation review pressure for the contextual factors and legal and licensing agreement feasibility for the organizational factors.

Table 1. Categorization of factors

\begin{tabular}{l|c|c|c}
\hline \multicolumn{1}{|c|}{ Factors } & Contextual category & Organizational category & Individual category \\
\hline Accreditation review pressure & $* *$ & $* *$ & \\
\hline Legal and licensing agreement feasibility & & & $* *$ \\
\hline Internal User participation & & & \\
\hline$* *$ New or Unexpected fators foun which are not in the preliminary reserch or erlier studies
\end{tabular}

**New or Unexpected factors found which are not in the preliminary research or earlier studies.

This CRM implementation is considered particularly successful even though it involved only internal user participation. Most studies about CRM have reported that to be successful, these systems must involve both internal and external user participation during their implementation. Our findings about user participation contradict the previous research.

Further explanations about how each of the new or unexpected factors were found and developed are provided below.

\section{Accreditation Review Pressure}

The state SBDC strives to attain quality standards in order to maintain its accreditation from the US SBA's ASBDC (Accreditation of Small Business Development Centers). We found that $63 \%$ (12 out of 19) of interviewees recognized that the problems with the transmission of data were critical to the accreditation renewal. All the eligible comparable peer institutions have implemented the CRM systems to resolve these problems. We also found that $89 \%$ (17 out of 19) of interviewees mentioned the need of a system to report performance so the accreditation team can assess the performance. Because of that, the state SBDC felt the pressure to initiate CRM implementation in order to meet the quality standards of its comparable institutions. We found that $58 \%$ (11 out of 19) of the respondents explained that the accreditation team has very high expectations. Therefore, the accreditation is received through a rigorous and 
comprehensive review process and the state SBDC needs to maintain its accreditation in order to benefit from US Federal funding and grants. We finally found that $74 \%$ (14 out of 19) of participants mentioned a potential loss of accreditation. By losing its accreditation, the state SBDC will find itself isolated. The worst scenario is that the state SBDC can be eventually excluded from the market. These are reflected by some of the declarations collected during the interview:

The problems with the transmission of data was critical to our accreditation. We made an accreditation visit to see how the accreditation team used the reporting data in their determination of the quality of all programs. We understand that we may lose our accreditation. The period of accreditation review is coming quickly, but the old system so called "1-Site" was problematic. We need a system to report performance, so the accreditation team can assess our performance.

\section{Legal and Policy Agreement Feasibility}

This section deals with the bidding procedure of the public institutions in the state and the software licensing verification. When a public institution desires to buy equipment, items, food, etc., bids or proposals should be solicited from a minimum of three vendors as required by the state law and policy. Since the state SBDC is using federal government and local university funding to operate, it does not have enough resources to interpret the state law and licensing agreement contract. Therefore, we found that 100\% (19 out of 19) of consultants specified that the state SBDC referred to the CBPA and the local university legal and purchasing department during the CRM implementation process. As shown in our findings, 74\% (14 out of 19) reported that the local university legal purchasing team reviewed the bid process and the contract between the state SBDC and the CRM vendor.

We found that both parties (CRM vendor and the state SBDC) licensing agreement involved a contract between a software vendor and a software user or buyer. We also found that $84 \%$ (16 out of 19) of respondents said that the licensing agreement between the CRM vendor and the state SBDC was reviewed by the local university purchasing department. The decision of purchasing CRM was approved by the local university legal purchasing department. The following statement derived from the interviews explained these findings:

We received advice from a legal technology knowledge person. We do not have enough technological infrastructure and personnel to have a customized system. It is why the legal purchasing department of the CBPA was involved. The legal purchasing team reviewed the bid process and the contract. Also, the legal purchasing department reviewed and approved the CRM licensing agreement.

\section{User Participation}

The importance of user participation in CRM implementation at the state SBDC was recognized. At the beginning, the state SBDC lead center created a project team. This was part of our findings because $84 \%$ (16 out of 19) mentioned that the state SBDC implementation of CRM involved the establishment of a project team. We found that $68 \%$ (13 out of 19) of consultants said they were included in conference call to discuss the purchasing decision. The state SBDC lead center understood the consultant needs and took those into account during the purchasing decision. We found that $89 \%$ (17 out of 19) of consultants mentioned that there was a vote taken before the final buying decision was made. Some consultants did not actively participate in the CRM implementation decision. However, we found that $89 \%$ (17 out of 19) of consultants attended the software demonstration session. In successful CRM implementation project, users should take part in the system acquisition and implementation phase, so as to commit themselves and develop realistic expectations about the system. A highlight from our interviews showed supports these findings.

We considered user needs in the CRM purchasing decision. Therefore, we attended a CRM software demonstration session. The state director, possibly the assistant state director, had more direct participation. I have actively participated in the system's buying decision process. We had a conference call to discuss the purchasing of CRM. I do not participate in the national meeting. There was a vote taken and we decided that we would prefer CRM. The top management has not taken my opinion and my needs before deciding to buy and implement the CRM system. 


\section{DISCUSSION}

Accreditation review pressure was a contextual factor and an antecedent to the CRM implementation decision. This finding can be explained by the research conclusion of Kiang, Fisher, Chen, Fisher and Chi (2009) who mentioned that accreditation gives the organization prestige by placing it in a group of accredited institutions that meet strict quality standards. The accreditation of the US SBA's ASBDC should give the state SBDC external recognition. During the accreditation process, the state SBDC is judged by comparison with peer institutions which share the same standards in terms of mission and vision. Also, those comparable institutions should have similar structures, resources, size, and scope. Furthermore, those institutions must have comparable performance report tools and instruments. Since all the accredited SBDCs have implemented CRM systems, the state SBDC made the same decision in order to be committed to quality improvement and control prevention.

Legal and policy agreement feasibility was another organizational factor. We did not find legal and policy agreement feasibility as an implementation factor in the literature. Only, Siebert and Graevenitz (2010) examined this topic in another context. Therefore, Siebert and Graevenitz (2010) research can be used to explain this finding. The conventional wisdom is to select a vendor that has been mandated to provide the new software to the state SBDC after the approval of the legal purchasing department. The state SBDC undertook this legal and secure procedure before the effective deployment of the CRM software to avoid exposure to the patent thicket belonging to the CRM vendor. The legal department has competence to verify software licensing which takes place to ensure freedom to operate or to use a specific software or technology designed by another company (Siebert \& Graevenitz, 2010). Software licensing agreement was studied in the literature in connection with the patenting behavior in high technology sectors providing modular technologies such as semiconductors (Siebert \& Graevenitz, 2010). It has been theorized that firms in semiconductors industry use cross-licensing contracts because they are increasingly affected by patent thickets in which firms' patents mutually block the use of important technologies (Siebert \& Graevenitz, 2010).

Internal user participation was an individual factor. User participation has been recognized as a critical component of CRM implementation in this study. Furthermore, this study stands out from other CRM research because the state SBDC focused only on internal user participation, but its CRM implementation was still successful.

The state SBDC did not invite customers (external users) to participate in the implementation because of the complexity of inter-organizational cooperation. CRM is a cross-functional process which involves a participatory relationship between businesses and customers (Cooper, Gwin \& Wakefield, 2008). Even though CRM systems involve internal and external user participation during their implementation, the state SBDC was not able to include customers (SBs) representatives in the user teams. That means, the CRM implementation at the state SBDC was performed without taking into account their customer participation. The state SBDC did not focus on the important role of external users in its CRM implementation because of the level of conflict and resources required to achieve that goal. The state SBDC is dedicated to assisting existing or new SBs which have work responsibilities and divergent personal and business interests that may disrupt CRM implementation.

Our findings also corroborate with the proposition of Vadapalli and Mone (2000). The state SBDC state director played a coordinator role because she put in place an implementation project team. CBPA faculty member and staff who possess technological experience have been hired through a grant solicitation. The state SBDC director reports to the CBPA Dean's office. The state SBDC director plays the role of planning and steering committee since she decides the allocation of resources (financial, materials, time, location of the implementation, etc.) to the different entities involved in the implementation project. The end-user group consisted of representatives from the state SBDC consultants. The project team would, as usual, report to the state SBDC director who would in turn report to the stakeholders and the board of directors. The project team consisted of three members: the implementation process manager who came from the IS department of CBPA, another IS and IT specialist who came from the Technology office of CBPA, and the state SBDC associate director who is a CBPA faculty member.

The literature revealed that there are both collective user participation and individual user participation in IT implementation (Rasmussen, Christensen, Fjeldsted \& Hertzum, 2011). The state SBDC did not create a group of users to represent the users during the implementation process. We noticed that it was individual internal user participation. This may be explained by the way the consultants were dispersed and spread around the state. However, 
we found collective user participation at the state SBDC annual conference when the CRM vendor was convened to present the project and the advancement of the project to the state SBDC consultants, supervisors, CBPA faculty member, stakeholders and the researcher who assisted for the implementation. This is aligned with the findings of Hunton, Arnold \& Gibson, (2001). However, the basic selection criterion of Rasmussen et al. (2011) was not found in their study.

\section{CONCLUSION}

This work reports on the CRM system implementation process of a state SBDC. This study first concentrated on the theoretical foundation by showing the connection between UTAUT and CRM implementation in the IS literature. At the state SBDC, the lead center has involved different participants in the CRM implementation project in order to minimize the risk of failure. Action research was appropriate because there was a collaborative activity among a researcher, the consultants and the state SBDC lead center searching for solutions to CRM implementation problems.

The implementation of the CRM system at the state SBDC is about a formalized and mature software program. Our analysis revealed multiple understandings of the implementation factors that may be regarded as related to each other. The state SBDC used services of different experts during the strategic implementation of the CRM software program. It is recommended to the SBDC to continue in that direction by allowing IS experts in any future IT implementation project. As those experts did for the implementation of CRM, they will study the implementation process and the factors of implementation completion, and measure the implementation predictors.

\section{AUTHOR BIOGRAPHIES}

Assion Lawson-Body is a Professor of Information Systems in the College of Business and Public Administration, University of North Dakota. He received PhD from Laval University, Quebec, Canada. His publications have appeared in Journal of Computer Information Systems, Industrial Management and Data Systems, Journal of Electronic Commerce in Organizations, Journal of Computer-Mediated Communication, and Journal of Service Sciences.

Laurence Lawson-Body is an Instructor of Accountancy in the College of Business and Public Administration, University of North Dakota. She is a CPA holder. She also received MBA from University of North Dakota. Her publications have appeared in Journal of Computer Information Systems.

Dr. Lori Willoughby is the Chair of the Business Information Technology Department, Program Director for the Master of Science -- Information Systems, and Assistant Dean for the Graduate School at Minot State University. She received her $\mathrm{PhD}$ from Utah State University. Her publications have appeared in Journal of Computer Information Systems.

\section{REFERENCES}

Alshawi, S., Missi, F., \& Irani, Z. (2011). Organisational, technical and data quality factors in CRM adoption - SMEs perspective. Industrial Marketing Management, 40, 376-383.

Cooper, M.J., Gwin, C.F., \& Wakefield, K. L. (2008). Cross-functional interface and disruption in CRM projects: Is marketing from Venus and information systems from Mars? Journal of Business Research, 61, 292-299.

Garrido-Moreno, A., \& Padilla-Meléndez, A. (2011). Analyzing the impact of knowledge management on CRM success: The mediating effects of organizational factors. International Journal of Information Management, 31, 437- 444.

Garrido-Moreno, A., Lockett, N., \& Garcia-Morales, V. (2014). Paving the way for CRM success: The mediating role of knowledge management and organizational commitment. Information and Management, 51, 1031-1042.

Hunton, J.E., Arnold, V., \& Gibson, D. (2001). Collective user participation: a catalyst for group cohesion and perceived respect. International Journal of Accounting Information Systems, 2, 1-17.

Kiang, M.Y., Fisher, D.M., Chen, J-C., Fisher, S.A., \& Chi R.T. (2009). The application of SOM as a decision support tool to identify AACSB peer schools. Decision Support Systems, 47, 51-59.

Kock, N. (1998). Can communication medium limitations foster better group outcomes? an action research study. Information \& Management, 34, 1998, 295-305.

Lawson-Body, A., Willoughby, L., Lawson-Body, L., \& Kinvi, L. (2012). The critical success factors for public sector CRM implication. Journal of Computer Information Systems, 52, 2, 42-50 
Mahdavi, I., Cho, N., Shirazi, B., \& Sahebjamnia, N. (2008). Designing evolving user profile in e-CRM with dynamic clustering of Web documents. Data \& Knowledge Engineering, 65, 355-372.

Mendoza, L. E., Marius, A., Perez, M., \& Griman, A. C. (2007). Critical success factors for a customer relationship management strategy. Information and Software Technology, 49, 913-945.

Nair, A., Malhotra, M.K., Ahire, S. L. (2011). Toward a theory of managing context in Six Sigma process-improvement projects: An action research investigation. Journal of Operations Management, 29, 529-548.

Pai, J-C., \& Tu, F-M. (2011). The acceptance and use of customer relationship management (CRM) systems: An empirical study of distribution service industry in Taiwan. Expert Systems with Applications, 38, 579-584.

Porter, M. (2008). The Five Competitive Forces That Shape Strategy. Harvard Business Review, 1, 10-21.

Qu, Z., Zhang, H., \& Li, H. (2008). Determinants of online merchant rating: Content analysis of consumer comments about Yahoo merchants. Decision Support Systems, 46, 440-449.

Rasmussen, R., Christensen, A. S., Fjeldsted, T., \& Hertzum, M. (2011). Selecting users for participation in IT projects: Trading a representative sample for advocates and champions? Interacting with Computers, 23, 176-187.

Siebert, S. \& Graevenitz, G. V. (2010). Jostling for advantage or not: Choosing between patent portfolio races and ex ante licensing. Journal of Economic Behavior \& Organization, 73, 225-245.

Steel, M., Dubelaar, C. \& Ewing, M. T. (2013). Developing customized CRM projects: The role of industry norms, organizational context and customer expectations on CRM implementation. Industrial Marketing Management, 42, $1328-1344$.

Sumak, B., \& Sorgo, A. (2016). The acceptance and use of interactive whiteboards among teachers: Differences in UTAUT determinants between pre- and post-adopters. Computers in Human Behavior, 64, 602-620.

Tate, M., Evermann, J. \& Gable, G. (2015). An integrated framework for theories of individual attitudes toward technology. Information \& Management, 52, 710-727.

Vadapalli, A. \& Mone, M. A. (2000). Information technology project outcomes: user participation structures and the impact of organization behavior and human resource management issues. Journal of Engineering and Technology Management, $17,127-151$.

Waser, H. \& Johns, N. (2003). An evaluation of action research as a vehicle for individual and organizational development in the hotel industry. Hospitality Management, 22, 373-393.

Wastell, D., Kawalek, P., Langmead-Jones, P. \& Ormerod, R. (2004). Information systems and partnership in multi-agency networks: an action research project in crime reduction. Information and Organization, 14, 189-210. 